Maxillo facial AND Plastic Surgery

\title{
Retrospective epidemiological study of mandibular rotational types in patients with orthodontical malocclusion
}

\author{
Studio retrospettivo epidemiologico delle tipologie rotazionali mandibolari \\ in pazienti con malocclusione \\ S. SACCOMANNO'1, R. DELI', G. DI CINTIO², E. DE CORSO², G. PALUDETTI², C. GRIPPAUDO'1 \\ ${ }^{1}$ Department of Dental Clinic Catholic University of the Sacred Heart, Rome, Italy; ${ }^{2}$ Department of Head and Neck \\ Surgery, Otorhinolaryngology, "A. Gemelli" Hospital Foundation, Rome, Italy
}

\section{SUMMARY}

The primary aim of this study was to illustrate the prevalence of facial skeletal discrepancy in an Italian sample. Another aim was to evaluate the effectiveness of the sagittal skeletal discrepancy classification in order to establish a morphologic pattern of growth useful for diagnosis and prediction of therapeutic results. The authors considered a sample of 732 patients ( 426 females and 306 males) aged between 6 and 17 years old. Cephalometric parameters were evaluated in order to establish a relationship between sagittal skeletal discrepancy and the classification of facial rotations (Lavergne and Petrovic). Facial types with neutral mandibular growth direction were the most prevalent, and were most observed in classes I and II; the latter was more represented than others in our sample. Facial types with posterior mandibular growth direction were the most prevalent in class III. Sagittal skeletal discrepancy classification is not able to establish a specific facial type or predict an individual responsiveness to treatment.

KEY WORDS: Malocclusion classification • Growth rotation • Rotational type

\section{RIASSUNTO}

L'obiettivo principale di questo studio è stato quello di definire la prevalenza delle asimmetrie cranio-facciali nella popolazione italiana. Obbiettivo secondario è stato quello di valutare l'efficacia della classificazione delle asimmetrie scheletriche sul piano sagittale al fine di stabilire il pattern morfologico di crescita, utile per la diagnosi e la previsione dei risultati terapeutici. Gli autori hanno analizzato retrospettivamente 732 pazienti (426 donne, 306 maschi), di età compresi tra 6 e 17 anni. Sono stati quindi effettuati i vari tracciati cefalometrici per stabilire i rapporti scheletrico sagittali e la classificazione delle rotazioni facciali sec Lavergne e Petrovic. Le tipologie con la più alta prevalenza sono risultate essere quelle con una direzione neutrale di crescita mandibolare. Tali tipologie sono state quelle più frequentemente osservate sia in classe I sia in classe II (la classe malocclusiva maggiormente rappresentata). In classe III, invece, è stata osservata la più alta prevalenza di tipologie facciali con direzione posteriore di crescita mandibolare. In conclusione la classificazione delle asimmetrie craniofacciali non è in grado di stabilire una specifica tipologia rotazionale e predire la risposta individuale al trattamento.

PAROLE CHIAVE: Classificazione delle malocclusioni $\bullet$ Tipologie rotazionali

Acta Otorhinolaryngol Ital 2018;38:160-165

\section{Introduction}

The diagnosis of skeletal class in an orthodontic patient is in close relationship with its definition and classification. Many studies have emphasised that it is not possible to diagnose a skeletal class, thus establishing a correct treatment plan by taking a single cephalometric measurement into account. The evaluation of different angles and linear measurements based on several reference planes might be more accurate, but that is certainly a more complex evaluation method and requires difficult to learn analytical reasoning. The use of a flow chart can lead to classification, and thus to a skeletal diagnosis that takes into account several variables. In this way, a diagnostic guide is easier to learn and has lower error rate. In our epidemiological study, we considered a flow chart based on Petrovic et al. ${ }^{12}$ to classify the facial type of 732 patients and compared our data with the results of previous studies based 
on cephalometric measurements. The Strasbourg school system (Petrovic, Lavergne, Gasson and Stutzmann) ${ }^{34}$, derived from the concepts of Hasund's facial floating norms ${ }^{5}$, combines patients into 11 rotational types and 33 rotational groups, if vertical dimension is taken into account. The facial growth rotational groups are predictors of potential growth and individual responsiveness to treatment.

The aim of this study was to evaluate relationships between classification of skeletal discrepancy based only on sagittal measures and classification of Facial Rotational types.

\section{Materials and methods}

A total of 732 (426 female and 306 Male) patients of the Orthodontics Department of Catholic University of Rome were enrolled in the study. We used the following inclusion criteria: age between 6 and 17 years old; absence of systemic diseases; absence of malformations; no previous orthodontic or orthopaedic treatment.

For each patient, the following cephalometric measurements were considered:

- SNA, angle between the nasion-sella line and nasionpoint A line;

- SNB, angle between the nasion-sella line and nasionpoint B line;

- $\mathrm{ANB}$, angle between the nasion-point $\mathrm{A}$ line and nasion-point $\mathrm{B}$ line, values between 1 and 4 have been associated to the I skeletal class, the values $>4$ to II class and values $<1$ to the III class;

- ML/NSL, angle between the nasion-sella line and the mandibular plane (line passing through the gnathion tangent to the gonial angle);

- NL/NSL, angle between the nasion-sella line and the nasal line (anterior nasal spine to posterior nasal spine).

For calculation of rotational types, in addition to measurements performed on cephalometric tracings, the expected values of ML/NSL and NL/NSL were calculated by employing the following mathematical formulas:

- ML/NSL expected $=192-2(\mathrm{SNB})$;

- $\mathrm{NL} / \mathrm{NSL}$ expected $=(\mathrm{ML} / \mathrm{NSL}) / 2-7$.

Using these angles, we calculated the values, through which it was possible to identify the rotational growth type of the patient on the diagram prepared by Petrovic ${ }^{12}$. 11 rotational types can be distinguished and designated by trinomial label. In each label, the three successive symbols represent:

- growth rotation - P (posterior), R (neutral), A (anterior);

- potential difference in growth between the mandi- ble and maxilla - 1 (no difference), 2 (greater potential growth for maxillary bone) or 3 (greater potential growth for the mandible);

- sagittal interjaw relationship - D (distal), N (normal), M (mesial).

Additionally, each rotational type is subdivided according to the vertical dimension (OB for open bite, $\mathrm{N}$ for normal bite, DB for deep bite) in 33 rotational groups.

Petrovic and Stutzmann ${ }^{67}$ classified the data relating to the index of tissue growth into 6 auxologic categories corresponding to a mitotic mandibular index progressively increasing from 1 to 6 and identified a connection between the 6 growth categories and specific rotational types (Table I).

\section{Method error}

The assessment of methodological error for the cephalometric measurements was performed on 40 cephalograms that were randomly selected from the total of the observations using Dahlberg's formula ${ }^{8}$. The error for all measurements was less than 1.

\section{Results}

The study included 732 patients (58\% female) with a mean age of 9 years (Fig. 1). In this sample of orthodontic patients, skeletal class II, indicated by ANB angle value, was the most represented $(52 \%)$, followed by class I $(33 \%)$ and class III (15\%) (Fig. 2).

Figure 3 shows the prevalence of rotational types in our sample, where the most represented is the $\mathrm{R} 1 \mathrm{~N} 4^{\text {th }}$ category (20\%), followed by R2D $3^{\text {th }}$ category $(17 \%)$, A1N (15\%), P1N and A1D (13\%).

We compared sagittal skeletal class, indicated by the value of ANB, to the facial rotational types.

The results were (Fig. 4):

- In skeletal class I the most frequent rotational type was R1N (35\%) followed by A1N (27\%) and P1N (22\%). So these three types represented $84 \%$ of skeletal class I sub-group.

Table I. Relationship between growth category and rotational type.

\begin{tabular}{ll}
$\begin{array}{l}\text { Growth category } \\
\text { (Growth potential) }\end{array}$ & Rotational type \\
1 & P2D \\
2 & A2D; P1N \\
3 & R2D \\
4 & R1N \\
5 & A1D; A1N; P1M; R3M \\
6 & A3M; P3M \\
\hline
\end{tabular}




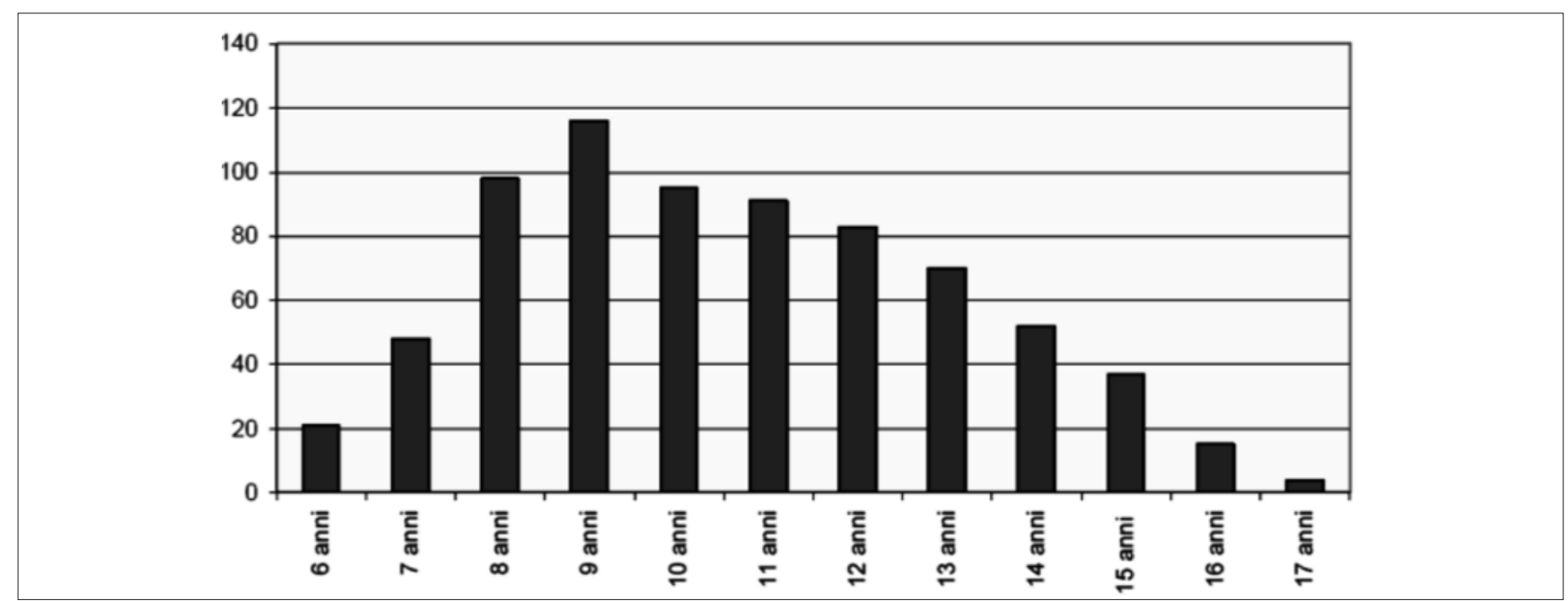

Fig. 1. Age distribution of the sample.

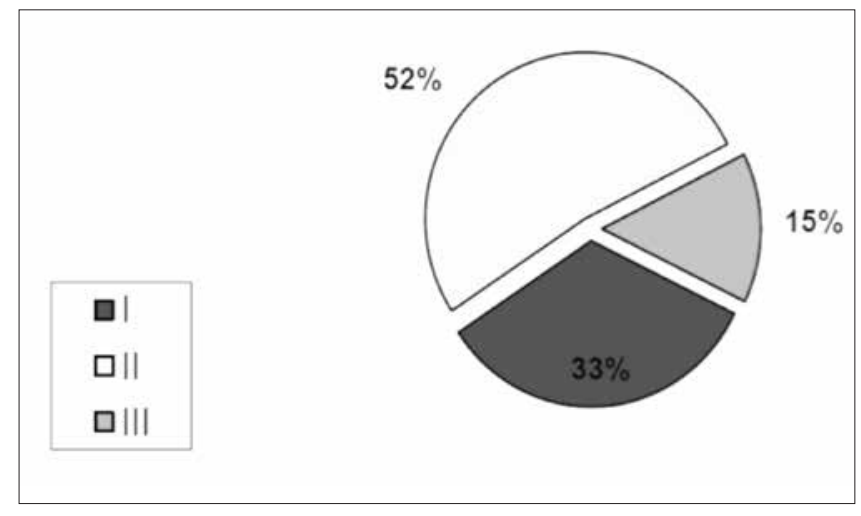

Fig. 2. Skeleton classes based on ANB calculation.
- In skeletal class II the most frequent rotational type was R2D (30\%) followed by A1D (25\%) and P2D (13\%). These three types represented $68 \%$ of skeletal class II subgroup. Types A1N and R1N represented 21\% of skeletal class II.

- In skeletal class III the most frequent rotational type was P1M (28\%) followed by P1N (25\%) and R3M (19\%). These three types represented $72 \%$ skeletal class III subgroup. Types A1N and R1N represented $20 \%$ of skeletal class III.

Growth neutral rotation was seen in $40 \%$ of the sample, and the anterior rotation in $34 \%$ and the posterior rotation in $25.5 \%$, and thus data are consistent with those reported

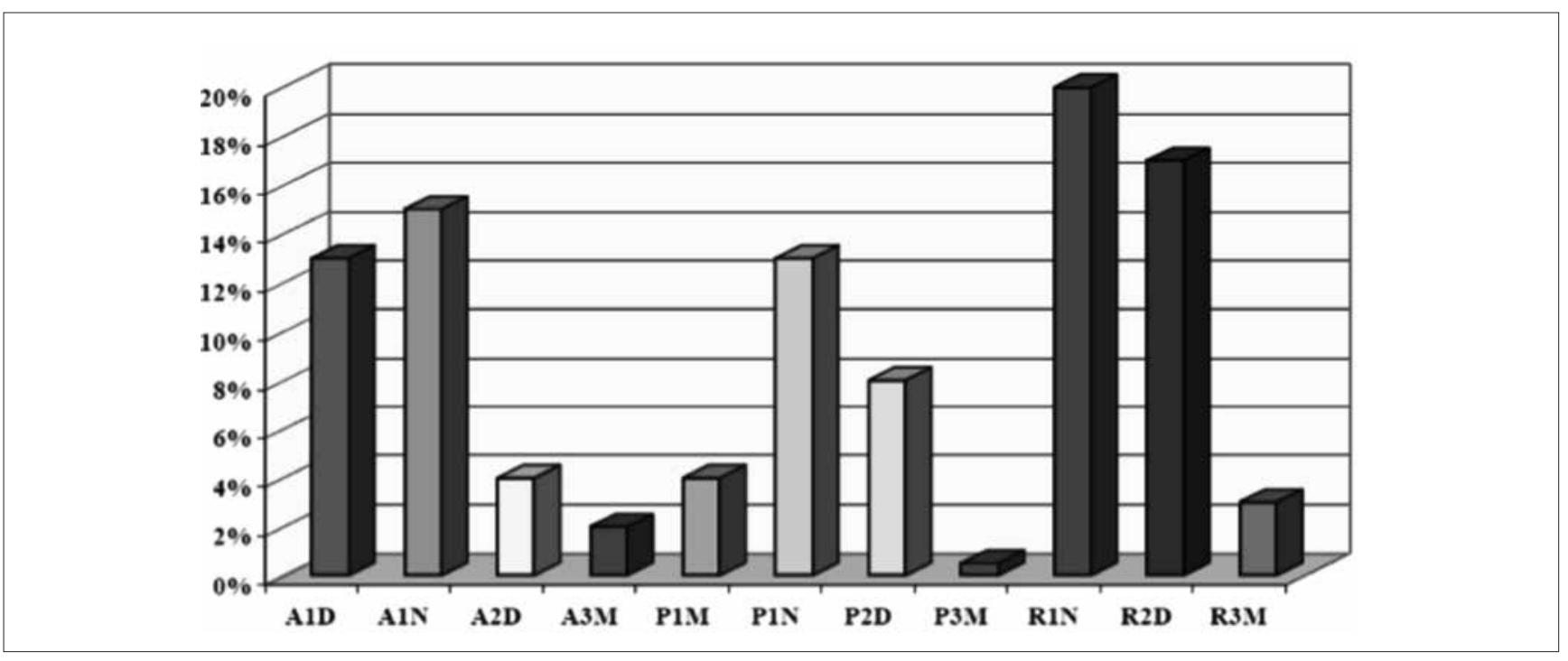

Fig. 3. Rotational types in the sample. 


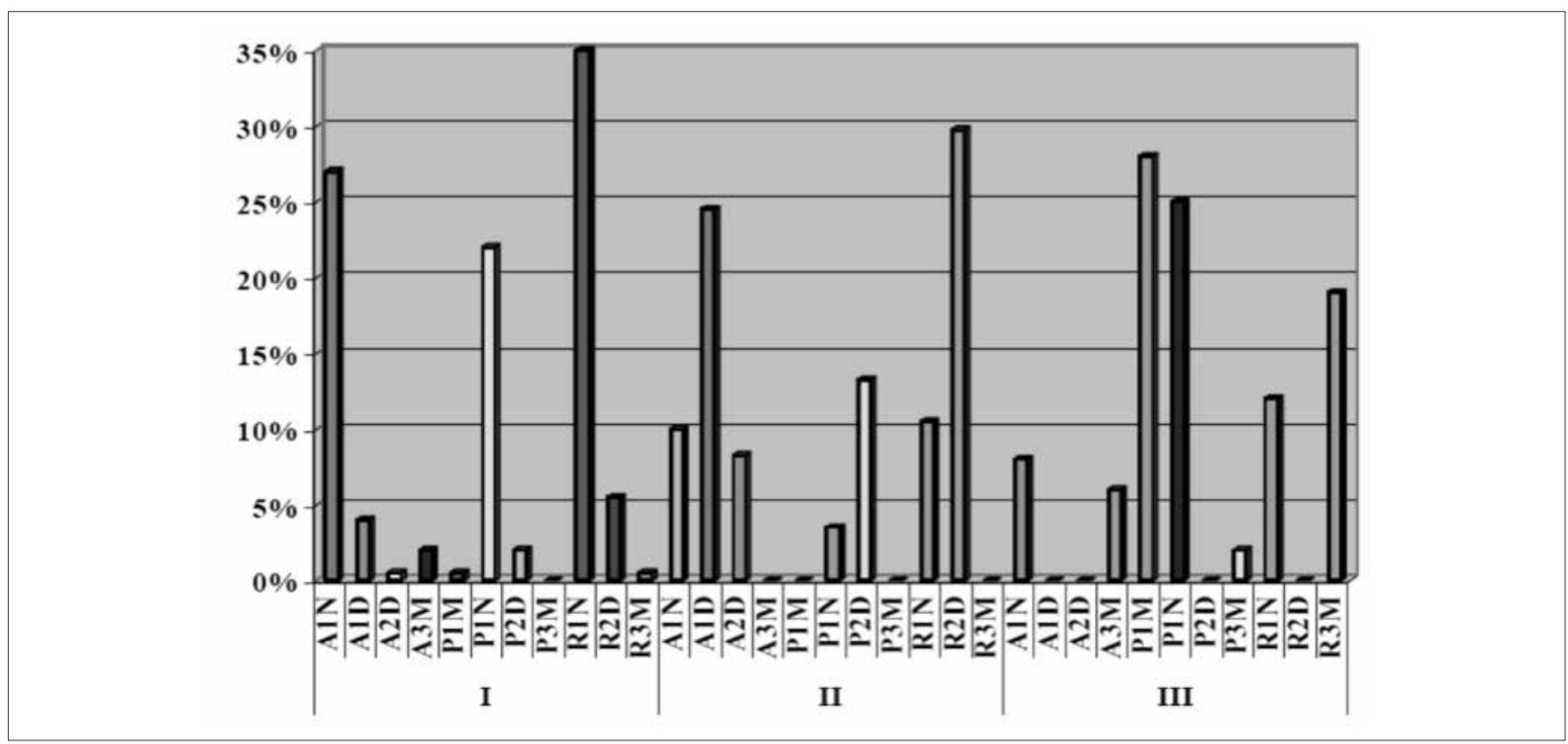

Fig. 4. Association between rotational types and skeleton classes.

by Lavergne and Petrovic (Neutral 39.5\%, anterior 35\%, posterior $25.5 \%$ ).

About $75 \%$ of patients showed a neutral or anterior rotational type. This patient population was classified as high growth category and was mainly grouped into skeletal classes I and II.

\section{Discussion}

Each type of mandibular growth category may include multiple rotational types as shown in Table I: for example, the $5^{\text {th }}$ category includes rotational types A1D, A1N, $\mathrm{P} 1 \mathrm{M}$ and R3M.

The Strasburg's school linked cephalometric architectural changes with a mitotic cellular index of patients belonging to each type, anticipating Rabie's theory ${ }^{910}$ and showed that there is an individual variation in natural or induced by mechanical stimuli cellular proliferation.

Skeletal class I of our sample was almost completely represented by the types $\mathrm{R} 1 \mathrm{~N}$ cat. $4, \mathrm{~A} 1 \mathrm{~N}$ cat. 5 and $\mathrm{P} 1 \mathrm{~N}$ cat. 2 $(84 \%)$ where the growth of the jaws was harmonic and in position normal. It is interesting to note that $10 \%$ of skeletal class I was represented by R2D and A1D types. These rotational types have distal inter-maxillary relationships, but normal ANB values.

In skeletal class II, sample data showed that $22 \%$ was composed of cases with normal jaw relationship and high growth category ( $\mathrm{R} 1 \mathrm{~N}$ and $\mathrm{A} 1 \mathrm{~N})$ even though these rotational types belong most frequently to skeletal class I without differen- tial growth of the jaws; $25 \%$ of skeletal class II was rotational type A1D where the mandible position is more posterior. Petrovic et al. ${ }^{3}$ in their studies of mitotic index showed that these patients had good potential growth. These findings are supported by several clinical studies ${ }^{11-13}$. A further $30 \%$ had a rotational type $\mathrm{R} 2 \mathrm{D}$, in which there is a differential potential growth and a distal position of the jaw, but the vertical neutrality makes this subgroup able to favorably respond to the therapy, if it is properly planned and conducted. The remaining $25 \%$ was represented by rotational types in which growth is not favourable for a resolution of class II (Petrovic et al. $\left.{ }^{311-13}\right)$. These findings are in agreement with the results of other studies that have evaluated the effect of orthodontic treatment on class II malocclusion.

O'Brien et al. ${ }^{14}$, in a randomised clinical trial (RCT) on the effectiveness of orthodontic treatment with TwinBlock appliance of class II malocclusion selected by presence of a minimum $7 \mathrm{~mm}$ overjet, reported that, although the Twinblock appliance appears to produce some skeletal changes, a substantial amount of this change was due to other factors. In conclusion, the author sustained that there is individual variation in growth that is not influenced by orthodontic "growth modification" treatment. Another study written by Tulloch et al. ${ }^{15}$ evaluated the increase in mandibular length and reported that $25 \%$ of the patients in control group had an additional growth of the mandible. Both RCTs, reported above, suggested that about $25 \%$ of the sample of class II malocclusion would have a significant increase of mandibular growth, and 
this increase might depend for an individual variations in growth.

$22 \%$ of the skeletal class II sample in our study was rotational type $\mathrm{A} 1 \mathrm{~N}$ and $\mathrm{R} 1 \mathrm{~N}$. These patients would respond to the therapy with a greater increase of skeletal growth, because of normal growth and normal jaw relationship. Comparing this data with those of the above studies, we hypothesise that individual growth factors can be identified by calculation of rotational type.

In a recent systematic review, Cozza et al. ${ }^{16}$, analysed mandibular changes produced by functional appliances in class II malocclusion. They reported clinically significant supplementary elongation in total mandibular length for two-thirds of the sample in the treated group compared with untreated group. In our sample of class II malocclusion, $75 \%$ was represented by rotational types $(\mathrm{A} 1 \mathrm{~N}$, R1N, A1D, R2D), which belong to categories responding favourably to treatment. These findings are comparable to those of Cozza et al.

In our study, $49 \%$ of skeletal class III subgroup (diagnosed by ANB angle) was represented by rotational types (P1M, R3M, P3M), which belong to high growth category (5 and 6). The $6 \%$ of the sample was $\mathrm{A} 3 \mathrm{M}$ rotational type, $6^{\text {th }}$ growth category, with mandibular growth in anterotation. The remaining sample was represented for $20 \%$ by rotational types $\mathrm{A} 1 \mathrm{~N}$ and $\mathrm{R} 1 \mathrm{~N}$ that usually belong to skeletal class I and for $25 \%$ by P1N, which belong to low growth category, although its verticality may cause therapeutic failures. A recent study by Cozza et al. ${ }^{17}$ evaluated the treatment and post-treatment effects of an orthopaedic protocol for class III malocclusion. Both treated group and control groups showed normal values of mandibular growth (respectively $3 \mathrm{~mm}$ and $6 \mathrm{~mm}$ ) in about $20 \%$ of cases, hence both dental and skeletal therapeutic results could be achieved.

\section{Conclusions}

This study emphasises the need to classify skeletal classes in different ways than wth ANB value. Rotational type classification leads to select more homogeneous groups that is able to reduce variability in the response to the same treatment protocol.

All studies reported above indicate the need to identify additional factors that can help to predict craniofacial growth. In fact, sagittal skeletal discrepancy classification is not able to establish a specific facial type or predict individual responsiveness to treatment.

This epidemiological study suggests that the rotational types that classify patients by several factors could be a reliable model of prediction facial growth. More clinical studies are needed to confirm the efficacy of treatment protocols in patients selected by criteria indicative of growth patterns.

\section{References}

1 Petrovic A, Lavergne J, Stutzmann J. Diagnosis and treatment in orthodontics: principles and decision diagrams. Orthod Fr 1987;58 Pt 2:517-42.

2 Petrovic A. Auxologic categorization and chronobiologic specification for the choices of appropriate orthodontic treatment-heritage paper. Am J Orthod Dentofac Orthop 1994;105:192-205.

3 Petrovic A, Lavergne J, Stutzmann J. Tissue-level growth and responsiveness potential, growth rotation, and treatment decision (181-223) In: Vig PS, Ribbens KA. Science and clinical judgement in orthodontics. Monograph 19, Cranio-Facial Growth Series. Michigan, USA: Ann. Arbor, Center for Human Growth and Development, University of Michigan; 1986. p. 249.

4 Petrovic A, Stutzmann J. Further investigations into the functioning of the "comparator" of the servosystem (respective positions of the upper and lower dental arches) in the control of the condylar cartilage growth rate and of the lengthening of the jaw (255-291). In: The biology of occlusal development. Monograph 6, Cranio-Facial Growth Series. Michigan, USA: Ann. Arbor, Center for Human Growth and Development, University of Michigan; 1977. p. 331.

5 Hasund A, Böe OE. Floating norms as guidance for the position of the lower incisors. Angle Orthod 1980;50:165-8.

6 Petrovic A, Stutzmann J, Lavergne J. Mechanisms of craniofacial growth and modus operandi of functional appliances: a cell-level and cybernetic approach to orthodontic decision making (13-73). Monograph 23, Cranio-Facial Growth Series. Michigan, USA: Ann. Arbor, Center for Human Growth and Development, University of Michigan; 1990. p. 232.

7 Petrovic A, Stutzmann J. The concept of the mandibular tissue-level growth potential and the responsiveness to a functional appliance (59-74). In: Graber Lee W. Orthodontics: state of the art, essence of the science. St Louis: CV Mosby; 1986. p. 421.

8 Dahlberg G. Statistical methods for medical and biological students. New York, NY: Interscience Publications; 1940.

9 Rabie AB, She TT, Harley VR. Forward mandibular positioning up-regulates SOX9 and type II collagen expression in the glenoid fossa. J Dent Res 2003;82:725-30.

10 Rabie AB, Wong L, Hägg U. Correlation of replicating cells and osteogenesis in the glenoid fossa during stepwise advancement. Am J Orthod Dentofacial Orthop 2003;123:521-6.

11 Petrovic A, Stutzmann J, Lavergne J, et al. Is it possibile to modulate the growth of the human mandible with a functional appliance? Bilt Udruz Orthodonata Jugosl 1988;21:15-20.

12 Petrovic A, Stutzmann J, Lavergne J. Effect of the functional appliances on the mandibular condylar cartilage (38-52). In: 
Graber TM. Physiologic principles of functional appliances. St Louis: CV Mosby; 1985. p. 86.

13 Petrovic A, Stutzmann J, Lavergne J. Mechanisms of craniofacial growth and modus operandi of functional appliances: a cell-level and cybernetic approach to orthodontic decision making (13-73). Monograph 23, Cranio-Facial Growth Series. Michigan, USA: Ann. Arbor, Center for Human Growth and Development, University of Michigan; 1990. p. 232.

14 O'Brien KD, Wright J, Conboy F, et al. Effectiveness of early orthodontic treatment with the Twin-block appliance: a multicenter, randomized controlled trial. Part 1: Dental and skeletal effects. Am J Orthod Dentofacial Orthop 2003;124:234-43.
15 Tulloch JFC, Philips C, Proffit WR. Benefit of early Class II treatment: Progress report of a two-phased randomized clinical trial. Am J Orthod Dentofacial Orthop 1998;113:62-72.

16 Cozza P, Baccetti T, Franchi L, et al. Mandibular changes produced by functional appliances in Class II malocclusion: A systematic review. Am J Orthod Dentofacial Orthop 2006;129:599.

17 Cozza P, Baccetti T, Mucedero M, et al. Treatment and posttreatment effects of facial mask combined with a bite-block appliance in Class III malocclusion. Am J Orthod Dentofacial Orthop 2010;138:300-10.

Received: March 20, 2017 - Accepted: June 12, 2017

Address for correspondence: Sabina Saccomanno, Department of Head and Neck Surgery, Catholic University "A. Gemelli”, "A. Gemelli" Hospital Foundation, 1.go F. Vito 1, 00168 Rome. Italy. Email: sabinasaccomanno@hotmail.it 